\title{
Long Term World Energy Demand and the Planet Response
}

Piergiulio Avanzini

CLENERGY - via Volta 27, Genova, Italy

Corresponding Author Email: piergiulio.avanzini@ clenergysas.eu

https://doi.org/10.18280/ti-ijes.640104

Received: 23 November 2019

Accepted: 2 February 2020

\section{Keywords:}

energy strategy, energy scenarios, energy technology

\begin{abstract}
The paper reports the contribution by Piergiulio Avanzini to the Round Table "Scelte Politiche e Teccniche su Energia, Ambiente, Lavoro " (Political and Technical choices on Energy, Environment, Jobs) held in Matera (Italy), on June $13^{\text {th }} 2019$ in the frame of the 4th AIGE/IIETA International Conference and 13th AIGE 2019 Conference on "Energy Conversion, Management, Recovery, Saving, Storage and Renewable Systems".
\end{abstract}

\section{INTRODUCTION}

At the 2nd AIGE Conference (Pisa 2008) I gave a contribution entitled: "Strategy for research on energy technologies of the XXI century: a long-term look" authors Piergiulio Avanzini and Andrea Del Giudice [1]. Inside there is a long-term scenario of the commitment of energy technologies with respect to the availability of resources. The model was based on data available in that year, in terms of probable reserves of sources and their consumption to meet the expected energy demand. The latter parameter was evaluated taking into account the expected growth of the world population. Other assumptions were the development of clean coal technologies and fourth-generation nuclear power plants.

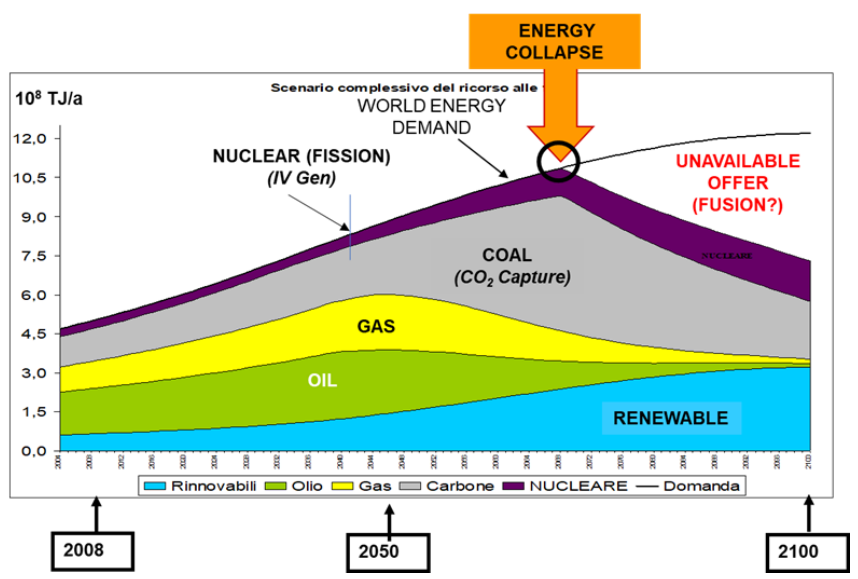

Figure 1. The most probable scenario in 2008

At that time the research effort on these technologies was working well.

The scenario of 2008 is shown in Figure 1 represents the most reasonable forecast considering the hypotheses formulated and shows a criticality (energy collapse) located between 2060 and 2070; period in which the demand starts to not be satisfied by the supply of sources and technologies. The depletion of world oil and gas reserves should have been offset by the increase in new generation nuclear and coal technologies and a physiological appeal to renewable technologies. The latter had an upper limit due to saturation [2].

My collaborators and I left this kind of studies a year later because they had no impact on the research community. After 10 years I decided to look again at the model considering how the 2008 hypotheses have changed.

\section{UP DATING THE FORECAST}

What happened in the meantime is:

- Substantially the world's fossil fuel reserves have not increased

- Advanced nuclear and clean coal technologies have not been proposed.

- World energy demand is increasing faster than in 2008

- Expectation towards renewable technologies is stronger

- Nuclear fusion research has not advanced substantially.

- There is a strong correlation between world population growth, growth in Gross Domestic Product (GDP) and energy demand (Figure 2)

The most reasonable scenario resulting from our model is shown in Figure 3.

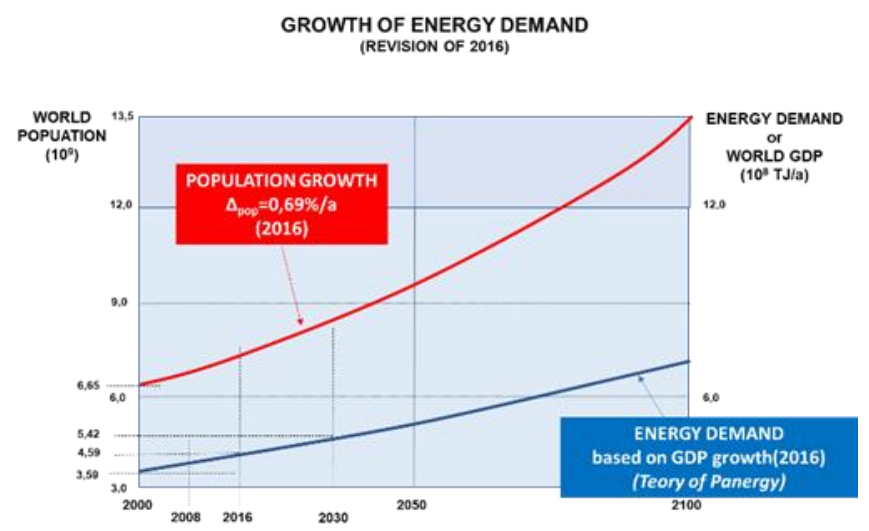

Figure 2. World population, GDP and energy demand 


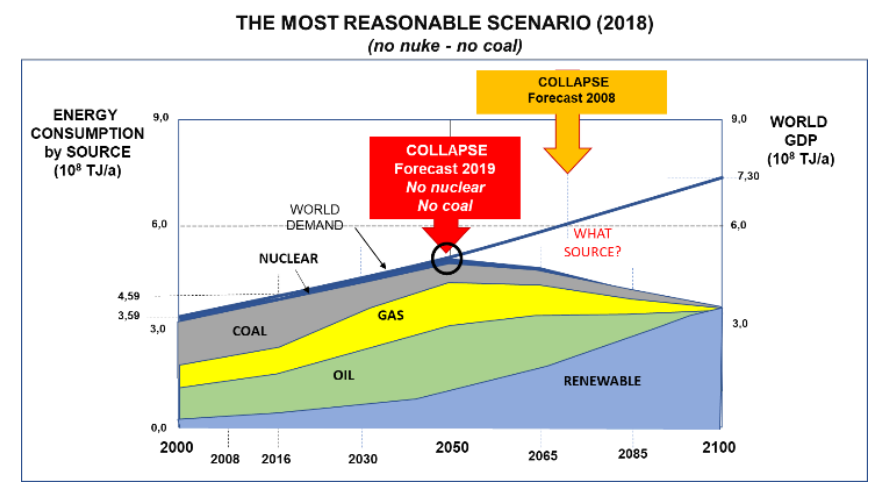

Figure 3. The 2019 scenario

According to this model the Energy Collapse is more critical than the Environmental Collapse due to climate change.

The maximum available renewable energy is determined by the assumptions made in 2008 which are summarized in Figure 4.

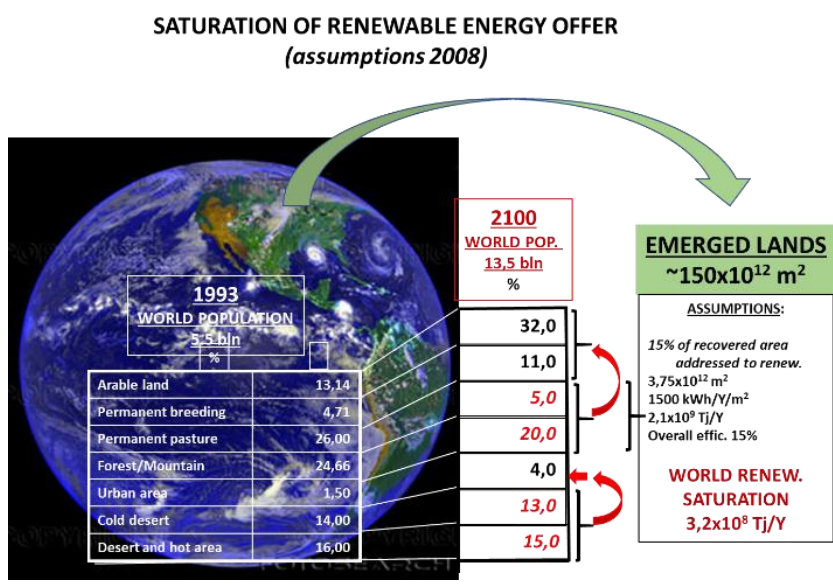

Figure 4. Maximum renewable offer expected

The saturation level is reasonable considering the actual and expected use of territory (emerged lands) and the reasonable level of efficiency at which solar radiation impacting the territory can be used. Under these considerations the maximum expected renewable contribution is $3.2 \times 10^{8} \mathrm{TJ} / \mathrm{y}$ [3].

Now the question is what could we do to avoid the disaster? And, as a consequence, could we shortly develop renewable technologies capable to overcome the actual saturation of the planet resources?

And furtherly, could we hope to cover the overall 2100 demand? In this case the scenario should be that of Figure 5.

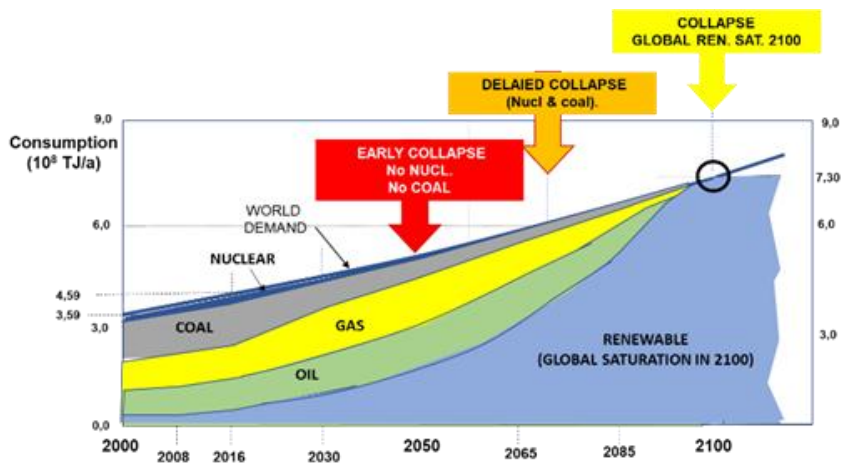

Figure 5. The full renewable scenario
In this scenario all the fossil reserves (excluded coal) are burned during the century and simultaneously replaced by renewables. The collapse is postponed to the year 2100 .

\section{A POSSIBLE WAY}

Our planet is actually covered by water for the $70 \%$. Recent studies on climate change state that part of the emerged lands could be submerged within this very century. As we have seen, even if this will not happen will not be possible to use more than $3.2 \times 108 \mathrm{TJ} / \mathrm{y}$ of the solar energy (direct and indirect) impacting the emerged lands [4].

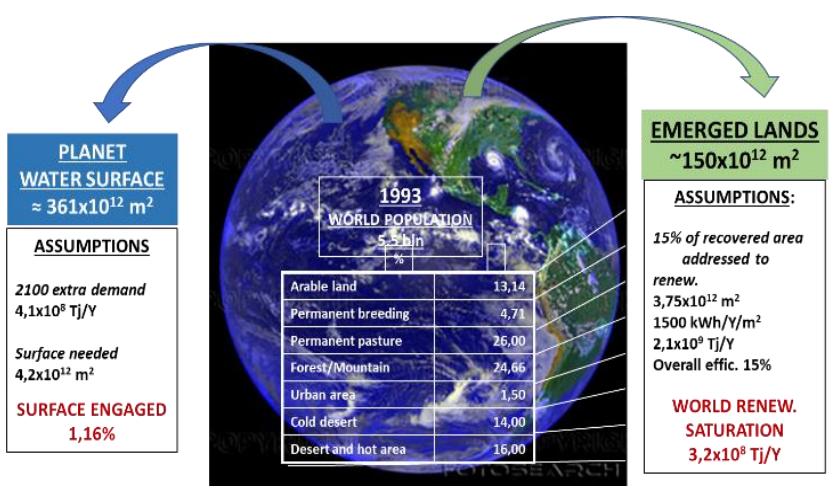

Figure 6. Marine renewable energy potential

We should look at ocean surface as a new space where to install our capture equipment. Figure 6 explains how, to achieve the extra demand foreseen in year $2100(4,1 \mathrm{x} 108 \mathrm{Tj} / \mathrm{y})$ the surface of capture is only $1,16 \%$ of the overall sea surface.

\section{A GLANCE TO ITALY}

Restricting the field to Italy, the potential of Marine Energy production is shown in Figure 7.

Considering the $1,16 \%$ of the Italian territorial waters, we could produce $0.36 \times 10^{6} \mathrm{GWh} / \mathrm{y}$, almost the same amount of the electricity production in 2017 [5].
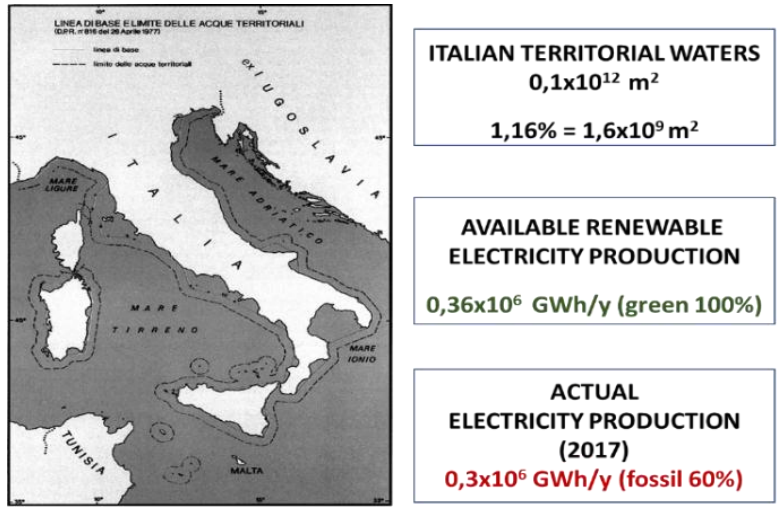

Figure 7. Marine energy potential in Italy

\section{THE TECHNOLOGIES AVAILABLE NOW}

Direct and indirect offshore solar technologies are different. Those who are dedicated to the production of electricity are, in general, very impactful on landscape and also the local bio- 
ecosystem is affected [6]. See, for example, Figures 8,9 and 10 which refer to PV, Wind and Solar Pond respectively.

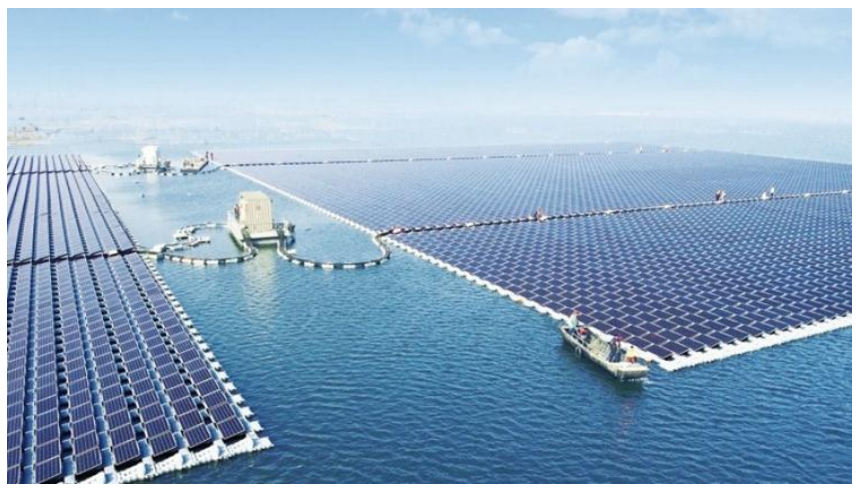

Figure 8. Offshore PV field

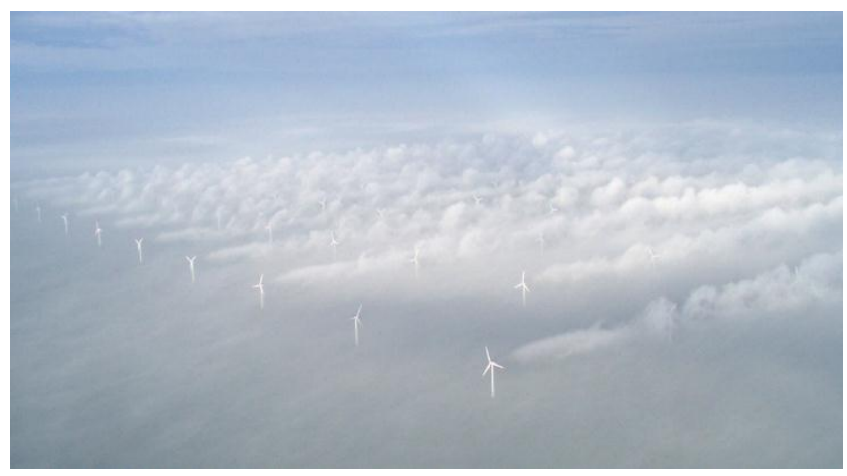

Figure 9. Offshore wind field

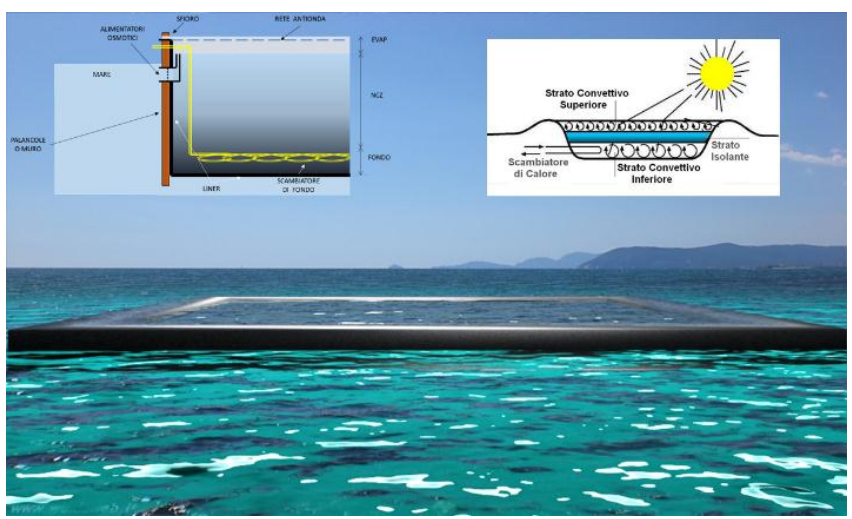

Figure 10. Offshore floating solar pond

Less impacting technologies are those that can be integrated in coastal infrastructures as shown in Figure 11.

\section{OSCILLATING WATER COLUMN WAVE GENERATOR - Working principle}

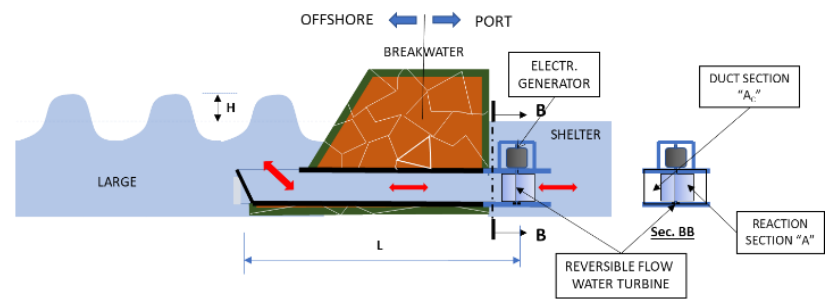

Figure 11. OWC wave generation

Figure 12 refers to the possibility of updating the wave generators inside the protection breakwater of the port of Genoa (Italy) for which a restructuring project is under discussion. It is a $10 \mathrm{~km}$ long structure with excellent exposure to the impact of the prevailing wave motion [7].

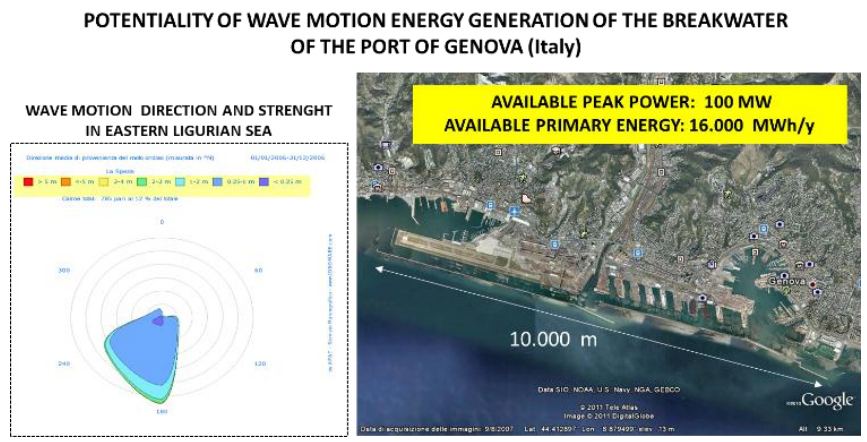

Figure 12. Breakwater potentiality of the port of genoa

It is interesting, especially for a country like Italy, to consider Sea as a thermal storage of solar energy so that it can be used for air conditioning of houses [8,9]. Figure 13 schematically shows a way in which it can be done. It is useful to consider that this is a characteristic with almost no environmental and landscape impact.

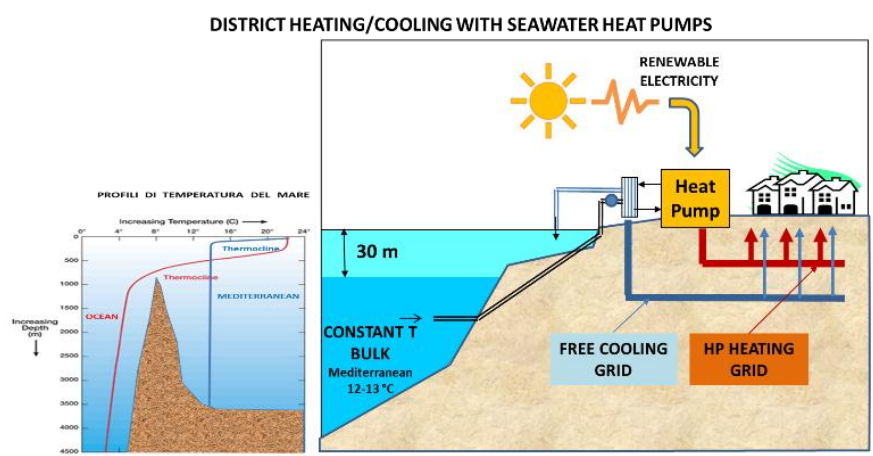

Figure 13. Marine technology for district air conditioning

\section{CONCLUSIONS}

In the coming decades the world will have to face not only climate changes, which exist regardless of whether they are anthropogenic or not, but also a growing scarcity of the usual energy sources, due to both hostility to many of them and depletion of reserves. The growing use of renewable technologies cannot be without impact. In my opinion, it is necessary to reconsider the technologies that have an impact in terms of risk and not in terms of structure (such as nuclear fission and coal combustion with carbon capture and storage).

In fact it is better to accept (from a planetary point of view) a local pollution due to a rare occurrence rather than a continuous and hopeless damage that accumulates without end.

\section{REFERENCES}

[1] Avanzini, P., Del Giudice, A. (2008). Strategy for research on energy technologies of the XXI century: A long-term look - II Congr. Naz. AIGE - Pisa 4, 5 settembre 2008.

[2] Avanzini, P. (2008). Assessment of Power Generation 
Systems through a Novel Tool: Panergy - II Congr. Naz. AIGE - Pisa 4, 5 settembre 2008.

[3] Avanzini, P. (2009). Valutazione comparativa delle tecnologie di genera zione elettrica oggi ed in prospettiva con il metodo della Panergia - $\mathrm{III}^{\circ}$ Congr. Naz. AIGE Parma 4, 5 giugno 2009.

[4] Avanzini, P. (2010). Power generation technologies assessment with an economic empirical approach: panergy. 33rd IAEE int.l Conference - paper 22 - Rio de Janeiro, Brazil.

[5] Avanzini, P. (2009). Assessment of power generation systems through a novel tool: Panergy. Int.Journal of
Heath and Tecn., 27(1): 157-161. https://doi.org/10.18280/ijht.270122

[6] Avanzini, P. (2010). Current Status and Future Trends of Scientific Research. Claudio Bertoli Editor - CNR DET 2nd Edition, pp. 3-30- Rome.

[7] Avanzini, P. (2011). Aggiornamento degli scenari energetici e della valutazione delle tecnologie a fine 2010 - V Congr. Naz. AIGE Modena 8,9 Giugno 2011.

[8] ENEA. (2018). Efficienza Energetica Rapporto Annuale RAEE 2018

[9] EUROSTAT (2018). Database https://ec.europa. eu/eurostat /data/ database. 